\title{
Evaluation of anti-diabetic effects of hydroalcoholic extract of green tea and cinnamon on streptozotocin-induced diabetic rats
}

\author{
Ghasem Shokri $^{1,2}$, Hamed Fathi ${ }^{1,3}$, Majid Jafari Sabet ${ }^{4}$, Nafiseh Nasri Nasrabadi ${ }^{1}$, Ramin Ataee ${ }^{1,5^{*}}$ \\ ${ }^{1}$ Pharmaceutical Sciences Research Center, Hemoglobinopathy Institute, Mazandaran University of Medical Sciences, \\ Sari, Iran \\ ${ }^{2}$ Student Research Committee, Mazandaran University of Medical Sciences, Sari, Iran \\ ${ }^{3}$ Department of Biology, Payame Noor University, Tehran, Iran \\ ${ }^{4}$ Department of Pharmacology, Iran University of Medical Sciences, Tehran, Iran \\ ${ }^{5}$ Talasemia Research Center, Hemoglobinopathy Institute, Mazandaran University of Medical Sciences, Sari, Iran
}

Received: Apr 11, 2015, Revised: May 10, 2015, Accepted: Jun 13, 2015

\begin{abstract}
Today diabetes is one of the most common diseases in the world that affects half of the world population. The use of medicinal herbs especially green tea and cinnamon has been taken into consideration for relieving the symptoms of diabetes, but there were some different ideas about their effectiveness. So, this study was conducted to evaluate the effect of cinnamon and green tea extract, individually and in combination, on blood glucose and weight loss in diabetic mice with Streptozotocin (STZ). The experiment was performed on 50 Wistar rats. A total of 50 rats were divided into 10 groups of 5 and STZ was injected at the dose of 40 $\mathrm{mg} / \mathrm{kg} /$ day for 5 days intraperitoneally. After diabetes induction, three groups received, 50, 100 and $200 \mathrm{mg}$ doses of green tea extract, three groups received 50, 100 and $200 \mathrm{mg}$ doses of cinnamon extract and three final groups received 50, 100 and $200 \mathrm{mg}$ doses of cinnamon and green tea in combination by gavages daily for 6 weeks. After each period of treatments, blood glucose and the weight of animals were determined. At the end of the sixth week, blood glucose and weight loss were improved in diabetic rats in a dose-dependent manner and the dose of $200 \mathrm{mg} / \mathrm{kg}$ extract cinnamon with green tea had the most appropriate synergic effect.
\end{abstract}

Keywords: Cinnamon, green tea, diabetes, streptozotocin.

\section{Introduction}

Diabetes mellitus (DM) is a group of metabolic diseases in which a person has high blood sugar with symptoms of frequent urination, increased thirst, increased hunger and weight loss. Untreated, diabetes can cause many complications as diabetic Ketoacidosis and nonketotic hyperosmolar coma (1). Today, diabetes is one of the most common diseases in the world that affects half of the world population. Every 30 seconds, one person in the world loses a leg due to lack of awareness of diabetes and diabetes controls $(2,3)$. Serious long-term complications include heart disease, kidney failure and damage to the eyes. Diabetes is due to either the pancreas not producing enough insulin or cells of body not respond properly to the insulin. Insulin is the principal hormone that regulates uptake of glucose from the blood into most cells (primarily muscle and fat cells, but not 
central nervous system cells) (2). Therefore, deficiency of insulin or the insensitivity of its receptors plays a central role in all forms of diabetes mellitus (2). Diabetes mellitus is a chronic disease, for which there is no known cure except in very specific situations (3). Management concentrates on keeping blood sugar levels as close to normal ("euglycemia") as possible, without causing hypoglycemia. This can usually be accomplished with diet, exercise, and use of appropriate medications (insulin in the case of type 1 diabetes; oral medications, as well as possibly insulin, in type 2 diabetes) (3).

A number of medicinal/culinary herbs have been reported to yield hypoglycemic effects in patients with diabetes. Cinnamon has been shown to potentiate the insulin effect through upregulation of the glucose uptake in cultured adipocytes (4). Also, there are some controversial reports about role of green tea in diabetes $(4,5)$. Some reports approved its' beneficial effect in diabetes and in some it is in doubt, for example, Ryu et al approved the effects of green tea on inflammation and arterial stiffness in diabetes patients. As results of their study, inflammatory markers, such as CRP and IL-6, were unchanged after green tea consumption, and neither were blood glucose, lipid profiles, insulin resistance, or serum adiponectin levels (5).

Although there were some literatures which show beneficial role of green tea and cinnamon in diabetes, these were not enough studies especially any precise study showing the effect of combinational treatment regime of these herbs in vivo; so, we have aimed this study to evaluate and compare the effect of these herbal extracts individually and in combination in animal model of diabetes type 1 .

\section{Materials and methods}

\section{Materials}

Streptozotocin, aluminum chloride $\left(\mathrm{AlCl}_{3}\right)$ and $\mathrm{KOH}$ were purchased from Merck Company (Germany). UV/V is VARIAN®50-SCAN spectrophotometer (Italy) and $1 \mathrm{~cm}$ quartz cells were used for all absorbance measurements. Levels of blood glucose were measured by Randox kits (Germany) and with Glucometer (Apocheck, Germany).

\section{Plant material}

We provided specified grade of green tea (Camellia sinesis L.) from Lahijan (Iran) and cinnamon wood (Cinnamomum verum) from India (Raja Co, Mumbai). Hydroalcholic extracts were prepared by percolation (7). Briefly, 200 grams of Cinnamomum verum stems and 200 grams Camellia sinesis L. leaves were milled, and extracted by maceration method with methanol. Extraction procedure was performed three times with an interval of 48 hours. The provided extracts were concentrated by rotary, and finally were dried completely using freeze dryer machine. After extraction with methanolic solvent, the resulting residues were extracted by water solvent, separately $(8,9)$.

\section{Determination of the total flavonoid}

For flavonoid determination of extract, aluminum chloride method was used. In this method quercetin (Sigma,Germany) was used as the standard and flavonoid contents were measured as quercetin equivalent. For this purpose, the calibration curve of quercetin was drawn (Figure 1). $0.5 \mathrm{~mL}$ of standard solution $(15,30,60,125$ and $250 \mu \mathrm{g} / \mathrm{ml}$ ) was taken into tubes, containing $1.5 \mathrm{~mL}$ ethanol. $0.1 \mathrm{~mL}$ of $\mathrm{KOH}$ $1 \mathrm{M}$ was added to the flask. After $5 \mathrm{~min}$, $0.1 \mathrm{~mL} 10 \% \mathrm{AlCl}_{3}$ and $2.8 \mathrm{~mL}$ of distilled water were added to the mixture. The 
absorbance was noted at $415 \mathrm{~nm}$ using UV-Visible spectrophotometer (12)

\section{Animals and treatment}

All procedures for animal workings have confirmed by Ethical committee of Deputy of Research, Mazandaran University of Medical Sciences (the number of project: 92-43). A total of 50 rats (5-6 weeks), 225$250 \mathrm{~g}$, originated from Albino race, were obtained from the Animals Laboratory Institute of Mazandaran University of Medical Sciences (Sari, Iran). The animal room temperature was $23 \pm 2{ }^{\circ} \mathrm{C}$, with a relative humidity of $55 \%$ and a $12 \mathrm{~h}$ daynight cycle. Housing, breeding and treatment of rats were in accordance with national and institutional guidelines (10). A total of 50 rats were divided into 10 groups of 5 animals each. STZ was injected at dose of $40 \mathrm{mg} / \mathrm{kg} /$ day for 5 days intraperitoneally (4). Two weeks later, three groups received 50, 100 and $200 \mathrm{mg}$ doses of green tea extract dissolved in dimethyl sulfoxide (DMSO) $10 \%$ by gavages daily for 6 weeks, respectively (16).

The other three groups were dosed daily 50, 100 and $200 \mathrm{mg}$ cinnamon extract by gavage for 6 weeks, respectively, and three final groups received 50, 100 and $200 \mathrm{mg}$ doses of cinnamon with green tea extract daily by gavages for 6 weeks, respectively. During the study period, animals were maintained in standard laboratory conditions (temperature $22{ }^{\circ} \mathrm{C}$ and light period - $12 \mathrm{~h}$ darkness). All data were analyzed using Student t-test and one-way ANOVA and for $\mathrm{EC}_{50}$ by Chi- Square(11).

\section{Determination of the Total Flavonoid}

For flavonoid determination of extract, Aluminum chloride method was used. In this method, quercetin (Sigma, Co. Germany), was used as the standard and flavonoid contents were measured as quercetin equivalent. For this purpose, the calibration curve of quercetin was drawn (Figure 1). $0.5 \mathrm{ml}$ of standard solution (15, $30,60,125$ and $250 \mu \mathrm{g} / \mathrm{ml}$ ) was taken into tubes, containing $1.5 \mathrm{~mL}$ ethanol. $0.1 \mathrm{~mL}$ of $\mathrm{KOH} 1 \mathrm{Molar}$ was added to the flask. After $5 \mathrm{~min}, 0.1 \mathrm{~mL} 10 \% \mathrm{AlCl}_{3}$ and $2.8 \mathrm{~mL}$ of distilled water were added to the mixture. The absorbance was noted at $415 \mathrm{~nm}$ using UV-Visible spectrophotometer (12).

\section{Results}

\section{Measurement of total flavonoid}

The total content of flavonoid in Camellia sinesis L. leaves extracts was $9.54 \pm 0.68$ $\mu \mathrm{g}$ quercetin per each $\mathrm{mg}$ extract and the total flavonoid content of extract of Cinnamomum verum wood was $8.27 \mu \mathrm{g}$ of quercetin in each mg extract.

Changes in blood glucose levels and weight induced by green tea extract

According to the experiments results, normal fasting blood glucose of rats in this experiment was determined as $95 \mathrm{mg} / \mathrm{dl}$ and the differences with this scale was estimated and compared.

As shown in Fig. 2, before two weeks of induction of diabetes in rats and with receiving the green tea extract, there isn't any significant difference among the groups in blood sugar levels, but after receiving the extract in the third week, significant difference at dose of $200 \mathrm{mg} / \mathrm{kg}$ of green extract with positive control has been observed $(\mathrm{P}<0.01)$ and at the $4^{\text {th }}$ and the $6^{\text {th }}$ weeks this significant difference was observed in all doses of green tea extract-(P $<0.001$ ) (Fig. 2).

Also changes in weight loss before the second week of receiving the extract was not significant, but in the third, fourth and sixth week of treatment, the differences were statistically significant (Fig. 3). 


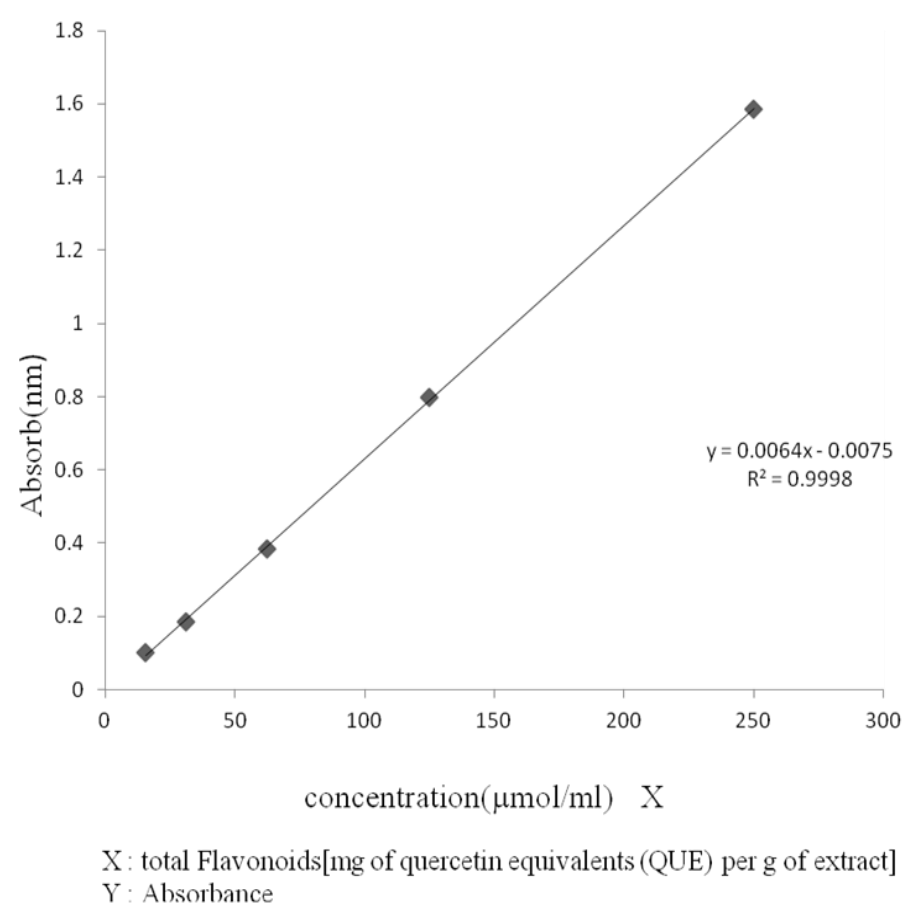

Figure 1 The standard curve of quercetin. To determine the total flavonoid content in the aqueous and methanolic watercress leaf extracts.

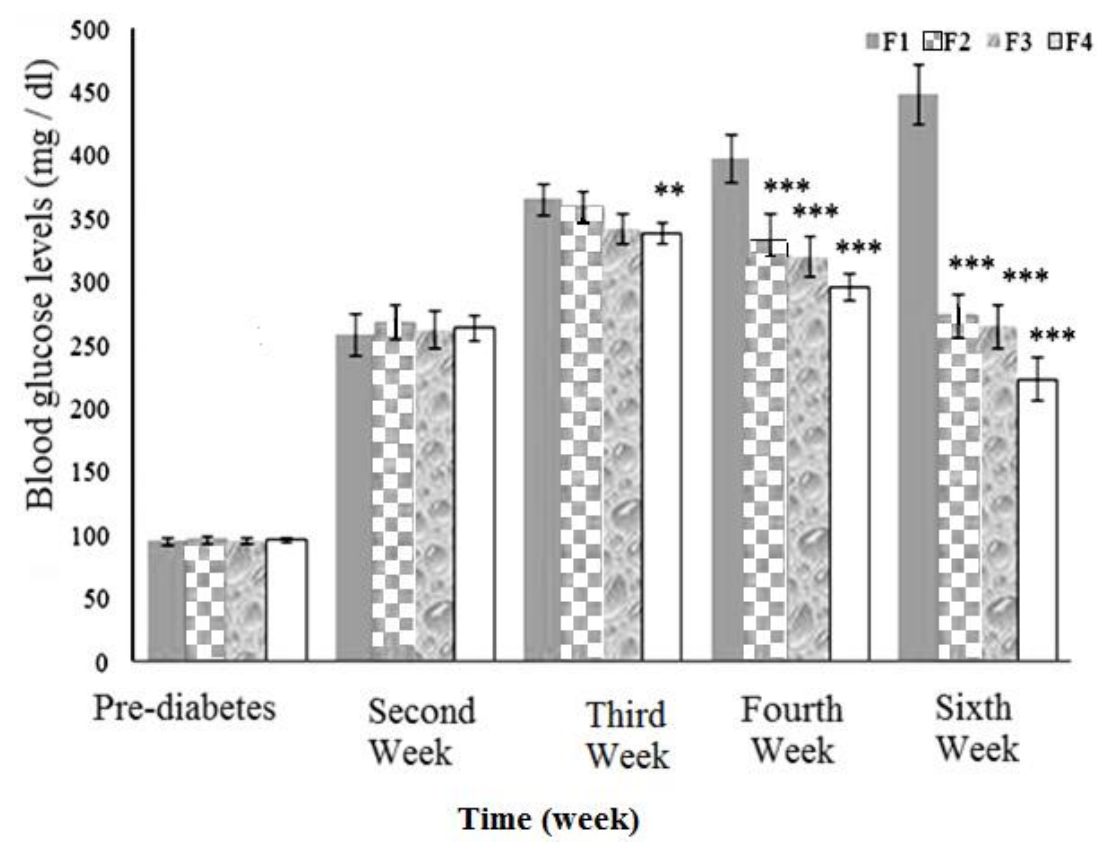

Figure 2 Comparison of blood glucose levels $(\mathrm{mg} / \mathrm{dl})$ between green tea extract groups with a control group F1: control diabetic group, F2: green tea extract $50 \mathrm{mg} / \mathrm{kg}$ F3: grean tea extract $100 \mathrm{mg} / \mathrm{kg}$ F4: grean tea extract $200 \mathrm{mg} / \mathrm{kg}$ : $* \mathrm{P}<0.05$ : Significant difference compared to diabetic control group., ${ }^{* *} \mathrm{P}<0.01$ : Significant difference compared to diabetic control group, $* * * \mathrm{P}<0.001$ : Significant difference compared to diabetic control group. 


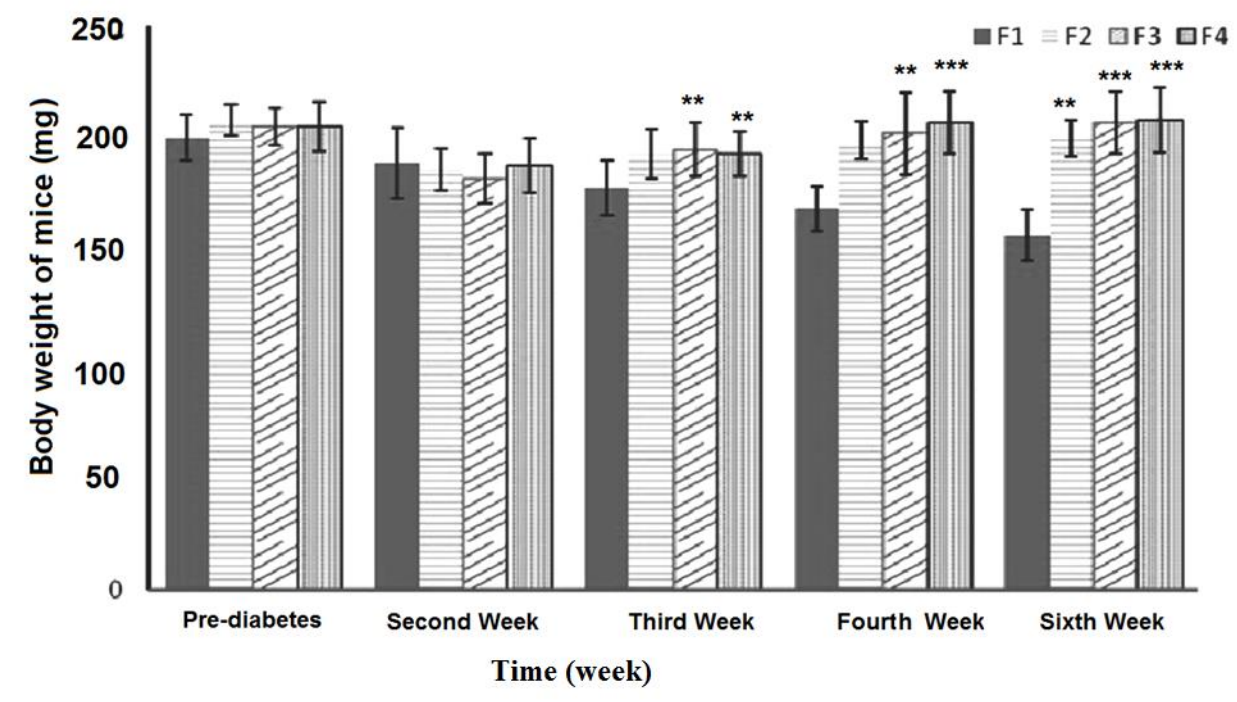

Figure 3 comparison of mice body weight $(\mathrm{mg})$ between green tea extract groups with a control group F1: control diabetic group,F2: green tea extract $50 \mathrm{mg} / \mathrm{kg} \mathrm{F} 3$ : grean tea extract $100 \mathrm{mg} / \mathrm{kg}$ F4: grean tea extract $200 \mathrm{mg} / \mathrm{kg}$ :* P<0.05: Significant difference compared to diabetic control group, ${ }^{*} \mathrm{P}<0.01$ : Significant difference compared to diabetic control group,,$* * * \mathrm{P}<0.001$ : Significant difference compared to diabetic control group

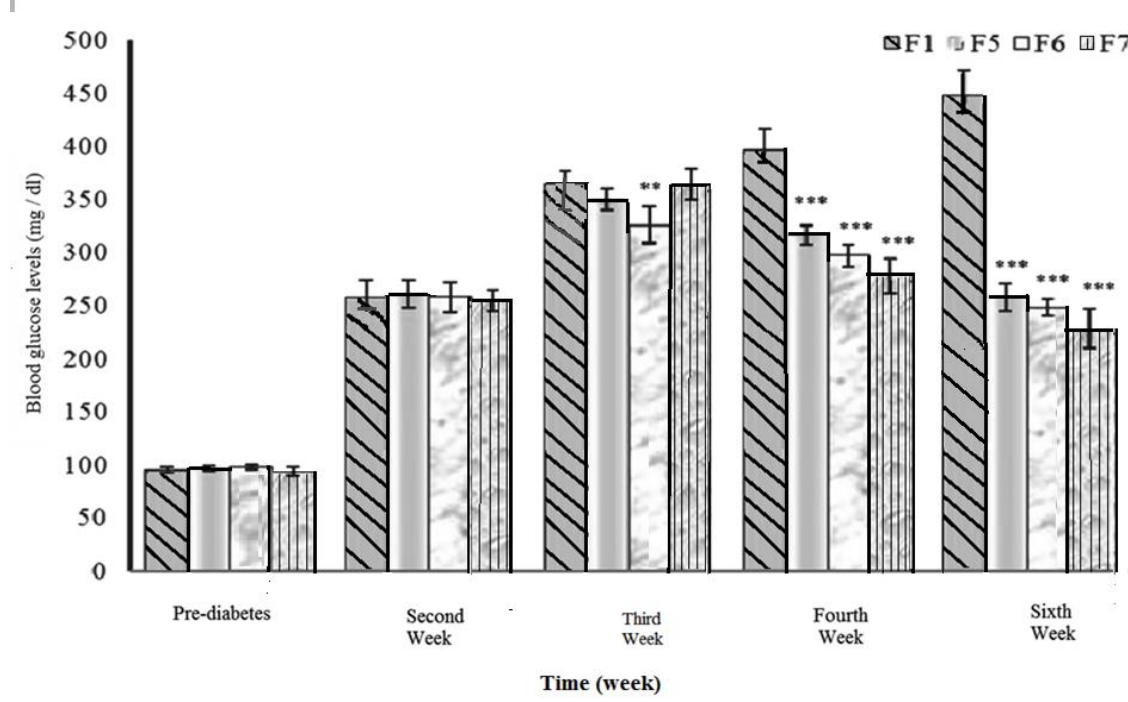

Figure 4 Comparison of blood glucose levels $(\mathrm{mg} / \mathrm{dl})$ between cinnamon extract groups with a control group F1: control diabetic group ,F5: cinnamon extract $50 \mathrm{mg} / \mathrm{kg} \mathrm{F6}$ : cinnamon extract $100 \mathrm{mg} / \mathrm{kg}$ F7: cinnamon extract $200 \mathrm{mg} / \mathrm{kg}$, ${ }^{*} \mathrm{P}<0.05$ : significant difference compared to diabetic control group., ${ }^{* *} \mathrm{P}<0.01$ : Significant difference compared to diabetic control group, ${ }^{* * *} \mathrm{P}<0.001$ : Significant difference compared to diabetic control group 


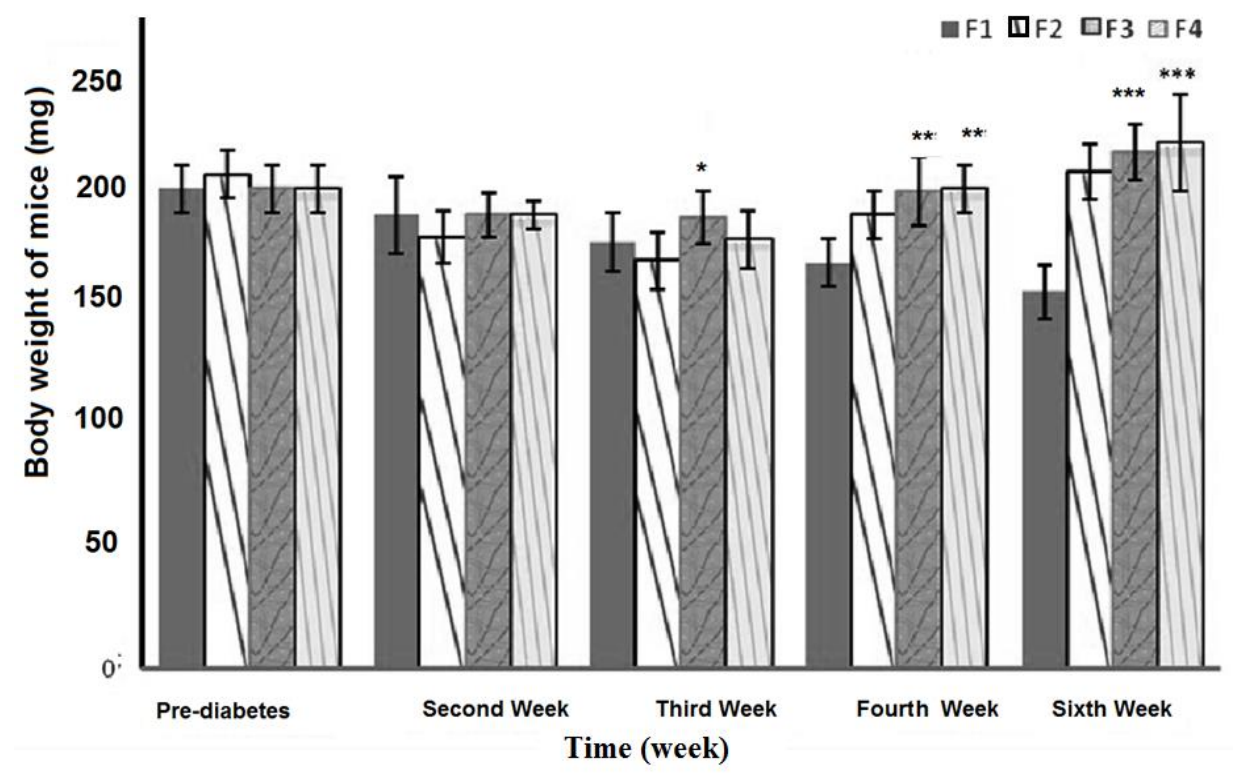

Figure 5 Comparison of mice body weight $(\mathrm{mg})$ between cinnamon extract groups with a control group F1: control diabetic group, F2: cinnamon extract $50 \mathrm{mg} / \mathrm{kg}$ F3: cinnamon extract $100 \mathrm{mg} / \mathrm{kg}$ F4: cinnamon extract $200 \mathrm{mg} / \mathrm{kg}$ :* P < 0.05: Significant difference compared to diabetic control group, $* * \mathrm{P}<0.01$ : Significant difference compared to diabetic control group, $* * * \mathrm{P}<0.001$ : Significant difference compared to diabetic control group

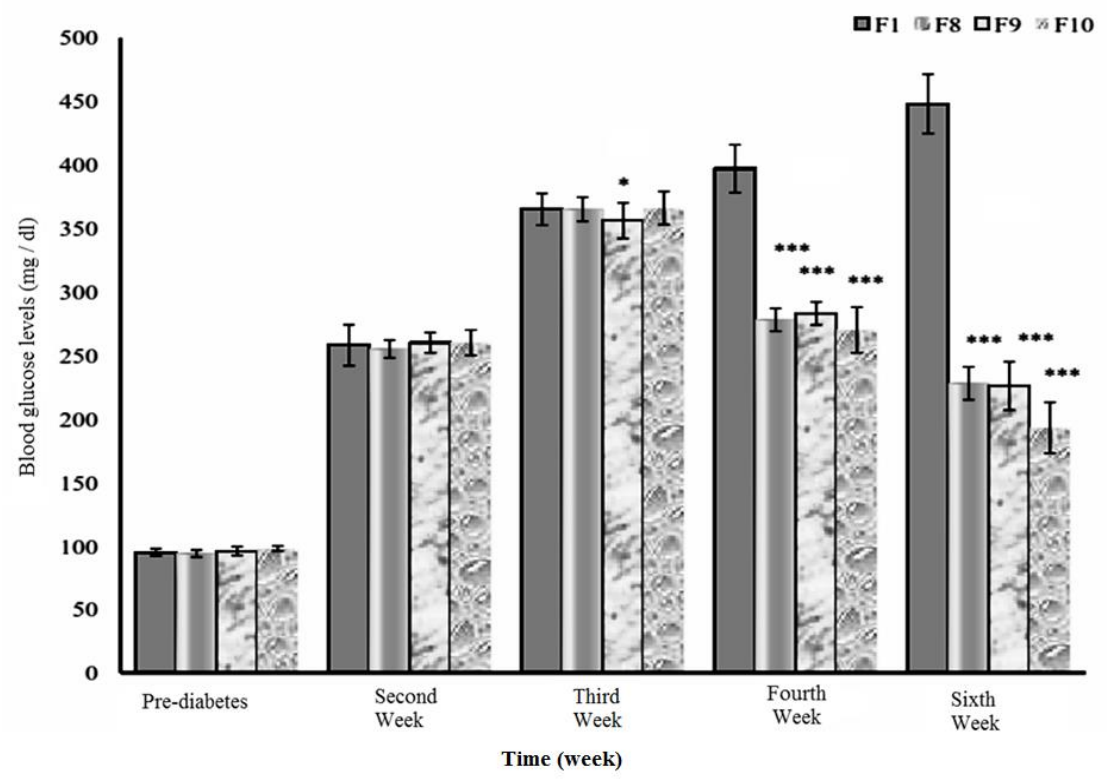

Figure 6 Comparison of blood glucose levels $(\mathrm{mg} / \mathrm{dl})$ between combination of cinnamon with green tea extract groups with a control group, F1: control diabetic group, F8: combination doses of cinnamon and green tea $(50 \mathrm{mg} / \mathrm{kg}), \mathrm{F} 9$ : combination doses of cinnamon and green tea $(100$ $\mathrm{mg} / \mathrm{kg})$, F10: combination doses of cinnamon and green tea $(200 \mathrm{mg} / \mathrm{kg}) * \mathrm{P}<0.05$ : Significant difference compared to diabetic control group, $* * \mathrm{P}<0.01$ : Significant difference compared to diabetic control group, $* * * \mathrm{P}<0.001$ : Significant difference compared to diabetic control group 
Changes in blood glucose levels and weight induced by cinnamon extract

Before induction of diabetes and before the third week of receiving the cinnamon extract, there was not any significant differences among the groups according to blood sugar levels $(\mathrm{P}>0.05)$, and in the third week, the significant result was observed at dose of $100 \mathrm{mg} / \mathrm{kg}$ and at the $4^{\text {th }}$ and the $6^{\text {th }}$ week of treatment, this difference was significant for all three doses $(\mathrm{P}<0.001)$ (Fig. 4). For the weight gain induction, before the third week of receiving the extract, there was no significant differences among the groups $(\mathrm{P}$ $>0.05)$ and in the third week, this difference was significant at dose of $100 \mathrm{mg} / \mathrm{kg}$ and in the 4 th and the 6th week, the results were significant in all three $\operatorname{doses}(\mathrm{P}<0.001)$ (Fig. 5).
Changes in blood glucose levels and weight induced by combined green tea, -cinnamon extract

Figure 6 shows the results of combinational therapy of green tea and cinnamon extract and as it is shown, in the fourth and sixth weeks of treatments, the differences with control group were more profound significant in all doses $(\mathrm{P}<0.001)$ and in figure 7 , the differences in body weight gain is exactly increased in the 4th and the 6 th weeks.

\section{Comparison between $E C_{50}$ of the groups}

As shown in figures 8 and 9, the $\mathrm{EC}_{50}$ of combinational therapy of cinnamon and green tea extracts decreased significantly blood glucose and gaining body weight after 6 weeks of treatment explain synergic effect between green tea and cinnamon.

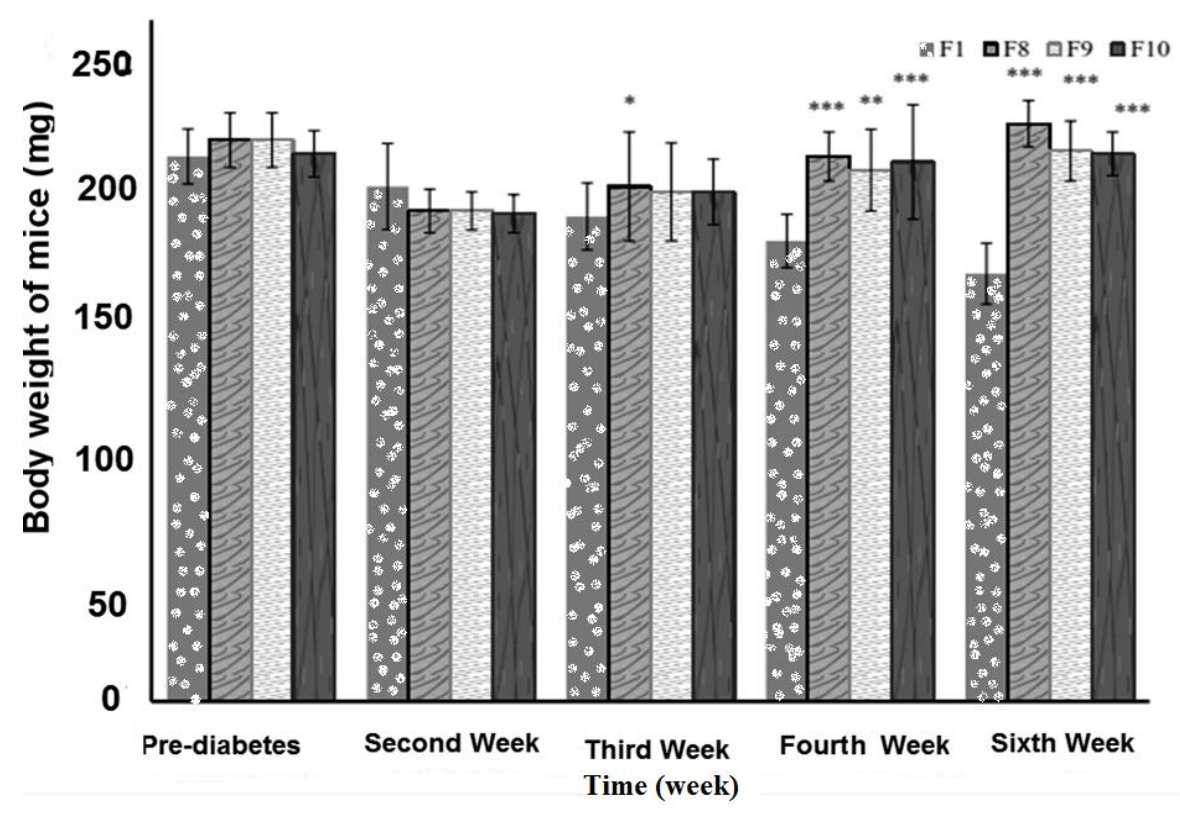

Figure 7 Comparison of mice body weight $(\mathrm{mg})$ between cinnamon extract groups with a control group F1: control diabetic group, F2: cinnamon extract $50 \mathrm{mg} / \mathrm{kg}$ F3: cinnamon extract $100 \mathrm{mg} / \mathrm{kg}$ F4: cinnamon extract $200 \mathrm{mg} / \mathrm{kg}$ : * P<0.05: Significant difference compared to diabetic control group, ${ }^{* *} \mathrm{P}<0.01$ : Significant difference compared to diabetic control group, $* * * \mathrm{P}<0.001$ : Significant difference compared to diabetic control group 


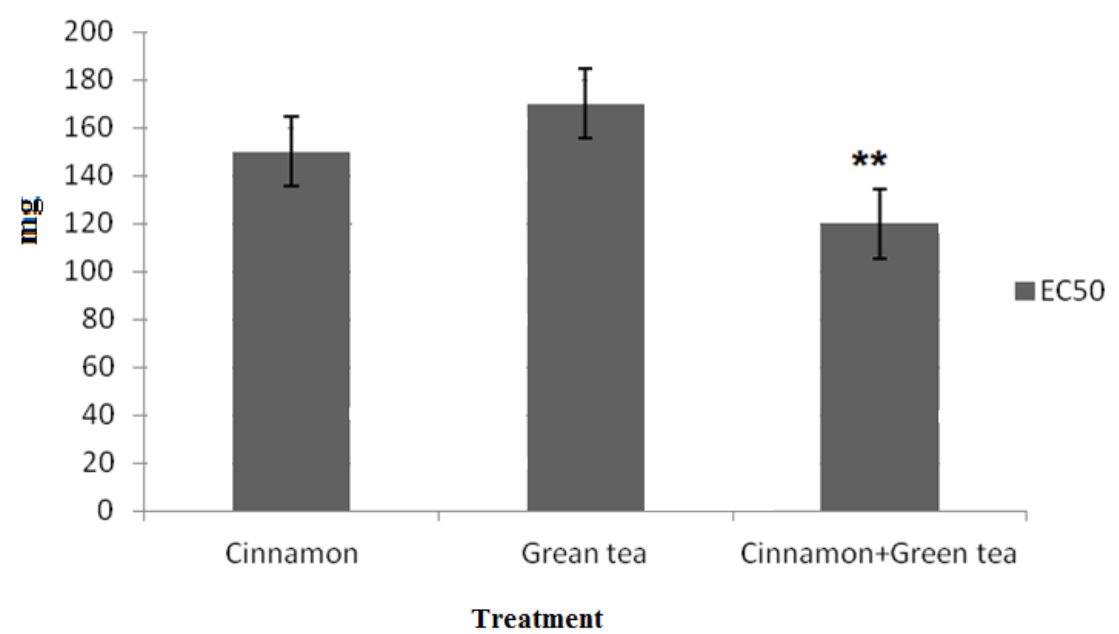

Figure 8 Comparison between $\mathrm{EC}_{50}$ of lowering blood glucose between three model of extract treatments at the $6^{\text {th }}$ week, analyzed by Chi-Square analysis $* * \mathrm{P}<0.01$

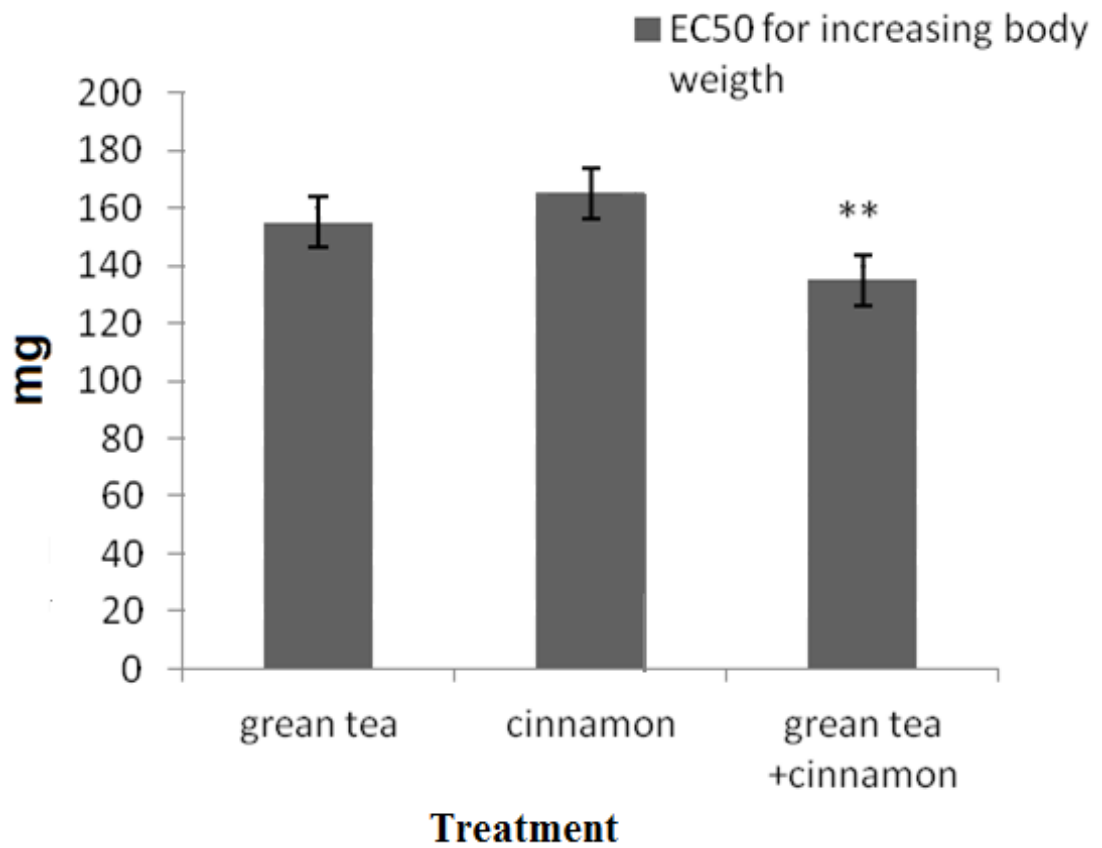

Figure 9 Comparison between $\mathrm{EC}_{50}$ of increasing body weight between three models of extract treatments at the $6^{\text {th }}$ week, analyzed by Chi-Square analysis $* * \mathrm{P}<0.01$ 


\section{Discussion}

This study compared the effects of three different routes of administration for green tea, cinnamon extract and combinational therapy of cinnamon extract and green tea, on blood glucose and body weight in diabetic rats. In all three categories of treatments, the extracts at doses of 50, 100 and $200 \mathrm{mg} / \mathrm{kg}$ reduced blood sugar and increased weight gain in the 4th and the 6th weeks of treatment in diabetic animals, and this improvement for combinational therapy regime was much more significant . Also considering the comparison of the results at the end of the sixth week, the dose of $200 \mathrm{mg} / \mathrm{kg}$ cinnamon extract - green tea was the most appropriate dose in vivo.

Mustata et al in a study, have reported that green tea therapy with vitamins $\mathrm{E}$ and $\mathrm{C}$ as antioxidant vitamins had no significant differences on glycemia, but inhibited the formation of hyperlipidemia and had improvement in retinal superoxide (12). Also, some other studies about the role of cinnamon in diabetes showed that it could reinforce insulin performance and improve insulin receptor phosphorylation $(13,14)$. Previously, Polanski et al. reported that cinnamon contains some constituents as cinnamon oil, euoginol, thyme oil and cumarin contemts which can enhance insulin secretion (15).

Tsubaki et al. showed that daily consumption of $1.5 \mathrm{~g}$ dried green tea powder in human diet was improved glucose tolerance in diabetics (16). In another study assaying combined effects of insulin and cinnamon, it was demonstrated that this therapeutically regime was more effective than each of them individually $(17,18)$.

Our study's results confirmed it and had some similarity with those studies which have shown anti diabetic action for herbal drugs (16).
Although our experiment has shown that cinnamon and green tea reduced blood glucose levels in diabetic animals, it has not demonstrated that these herbal medicines are as effective in non-diabetic individuals. The main reason for the better improvement of blood glucose in combinational therapy of cinnamon and green tea extracts, may be because of the synergic effect of polyphenols found in green tea and cinnamon which improved glucose metabolism, reduced food intake and reduced oxidative stress by streptozotocin and these polyphenols may especially increase glucose metabolism and decrease insulin resistance in adipocytes. Also, cinnamon and green tea may able to increase insulin secretion from pancreatic Langerhans islets cells, too. According to recent study either cinnamon and green tea extract can decrease blood sugar and induce weight gain individually and has been observed to have synergic effect in an animal model of type- 1 and with considering the absence of herbal profound hypoglycemic adverse effects,; this therapeutic regime can be suggested for the people with high risk of diabetes and as a complementary regime with antihyperglycemic drugs in diabetic patients. Besides, much more clinical trials are necessary to introduce these herbal extracts for diabetes therapeutics, especially with considering other biochemical parameters as their effect on insulin-blood levels and insulin-tolerance.

\section{Acknowledgments}

The authors like to thank Dr. M. Ghadami for author assistance and Department of Financial Field of Rresearch and Technology of Mazandaran University of Medical Sciences for financial supporting.

\section{Conflict of interest}


The authors declared no potential conflict of interest with respect to the authorship, and/or publication of this study.

\section{References}

1. Buse JB, Caprio S, Cefalu WT, Ceriello A, Del Prato $\mathrm{S}$, Inzucchi SE, et al. How do we define cure of diabetes?. Diabetes Care 2009;32:2133-5.

2. Association AD. Diagnosis and classification of diabetes mellitus. Diabetes Care 2008;31:55-60.

3. Nagao T, Tokimitsu I. A green tea extract high in catechins reduces body fat and cardiovascular risks in humans. Obesity 2007;15:1473-83.

4. Qin B, Ren M, Bajotto G, Oshida Y, Sato Y. Cinnamon extract (traditional herb) potentiates in vivo insulin-regulated glucose utilization via enhancing insulin signaling in rats. Diabetes Res Clinical Pract 2003;62:139-48.

5. Ryu O, Lee K, Kim H, Seo J, Kim S. Effects of green tea consumption on inflammation, insulin resistance and pulse wave velocity in type 2 diabetes patients. Diabetes Res Clinical Pract 2006;71:356-58.

6. Rossini AA, Chick WL, Appel MC, Cahill GF. Studies of streptozotocin-induced insulitis and diabetes. Proc Natl Acad Sci USA 1977;74:2485-9.

7. Singh J. Maceration, percolation and infusion techniques for the extraction of medicinal and aromatic plants. Extraction Technologies for Medicinal and Aromatic Plants 2008:67:32-35

8. Chan E, Chew Y. Antioxidant activity of Camellia sinensis leaves and tea from a lowland plantation in Malaysia. Food Chem 2007;102:1214-22.

9. Anesini C, Filip R. Total polyphenol content and antioxidant capacity of commercially available tea (Camellia sinensis) in Argentina. J Agric Food Chem 2008;56:9225-9.

10. Beaver BV. Environmental Enrichment for Laboratory Animals. ILARJ 1989;31:5-11.

11. Alp H, Celik MM, Altas M, Evliyaoglu O, Tokgoz O. Protective effects of beta glucan and gliclazide on brain tissue and sciatic nerve of diabetic rats induced by streptozosin. Exp Diabetes Res 2012;ID:230342.

12. Mustata GT, Biemel KM, Reihl O, Smith MAV is wanathan A. Paradoxical effects of green tea (Camellia sinensis) and antioxidant vitamins in diabetic rats improved retinopathy and renal mitochondrial defects but deterioration of collagen matrix glycoxidation and cross-linking. Diabetes 2005;54:517-26.

13. Jarvill-Taylor KJ, Graves DJ. A hydroxychalcone derived from cinnamon functions as a mimetic for insulin in 3T3-L1 adipocytes. J Am Coll Dent 2001;20:327-36

14. Onderoglu S, Erbil K.The Evaluation of Long-term Effects of Cinnamon Bark and Olive Leaf on Toxicity Induced by Streptozotocin Administration to Rats. J Pharm Pharmacol 1999;51:1305-12.

15. Imparl RJ, Polansky MM, Baedke DA, Ingebritsen TS, Anderson RA. Regulation of PTP-1 and insulin receptor kinase by fractions from cinnamon: implications for cinnamon regulation of insulin signalling. Horm Res 1998;50:177-82.

16. Tsuneki HIM, Terasawa M, Sasaoka T, Kimura I Effect of green tea on blood glucose levels and serum proteomic patterns in diabetic $(\mathrm{db} / \mathrm{db})$ mice and on glucose metabolism in healthy humans. BMC Pharmacol 2004;4:18-20.

17. Khan A, Khan M., Khattak KN, Anderson RA. Cinnamon improves glucose and lipids of people with type-2 diabetes. Diabetes Care 2003;26:3215-8.

18. Broadhurst CL, Anderson RA. Insulin-like biological activity of culinary and medicinal plant aqueous extracts in vitro. J Agric Food Chem 2000;48:849-52. 